\title{
Microstructure and Properties of $\mathrm{AgSnO}_{2}$ Composites by Accumulative Roll-bonding Process
}

\author{
Zhou Xiaolong ${ }^{1,2}, \quad$ Tao Qiying ${ }^{1}, \quad$ Zhou Yunhong ${ }^{1}$ \\ ${ }^{1}$ College of Materials and Engineering, Kunming University of Science and Technology, Kunming 650093, China; ${ }^{2}$ Key Laboratory of \\ Advanced Materials of Yunnan Province, Key Laboratory of Rare-Precious and Nonferrous Metal Advanced Materials of Ministry of Education, \\ Kunming University of Science and Technology, Kunming 650093, China
}

\begin{abstract}
AgSnO}_{2}$ composites prepared by a reaction synthesis method were investigated. The phases of $\mathrm{AgSnO}_{2}$ composites were analyzed using X-ray diffraction. The microstructure, density, hardness and resistivity of $\mathrm{AgSnO}_{2}$ composites after four-pass accumulative roll bonding (ARB) at $973 \mathrm{~K}$ were analyzed. Results show that microstructure and properties of $\mathrm{AgSnO}_{2}$ composites are significantly affected by the ARB process. The pass number of ARB decides the distribution of $\mathrm{SnO}_{2}$ particles in silver matrix. Roll bonding can promote the uniform distribution of $\mathrm{SnO}_{2}$ particles in silver matrix; however, it can also cause second agglomeration of $\mathrm{SnO}_{2}$ particles due to stacking. With the increasing of ARB number, the density and hardness increase. The resistivity has a slight reduction at the first-pass roll bonding, but then it increases with the increasing of ARB number.
\end{abstract}

Key words: reaction synthesis method; $\mathrm{AgSnO}_{2}$ composites; accumulative roll-bonding

As one of the main electrical contact materials, silver metal oxide $(\mathrm{AgMeO})$ composites have been widely used because of their excellent electrical contact characteristics $^{[1,2]}$. For a long time, the application of electrical contact materials is mainly focused on $\mathrm{AgCdO}$ composites in China. However, $\mathrm{Cd}$ is a kind of toxic substances. Therefore, a large amount of Ag alloy material and other composites used to replace $\mathrm{AgCdO}$ composites were investigated. As a better replacement to $\mathrm{AgCdO}$, $\mathrm{AgSnO}_{2}$ composites show excellent arc erosion resistance, abrasion resistance, good anti-welding and some unique electrical contact characteristics ${ }^{[3,4]}$. But some recent researches have found that some problems in application exist in $\mathrm{AgSnO}_{2}$ electrical contact materials ${ }^{[5,6]}$. In the electrical contact property test, $\mathrm{AgSnO}_{2}$ composites showed rising contact resistance with the increasing of current. Another problem is that $\mathrm{AgSnO}_{2}$ composites have a high hardness, which makes the forming difficult. Therefore, it may take a long time for $\mathrm{AgSnO}_{2}$ composites to be used as a replacement of $\mathrm{AgCdO}$.

Traditional researches focused on the composition design of electrical contact materials and achieved fruitful results, but very few researches considered the processing technology. Accumulative roll bonding (ARB) is effective means for the preparation of ultrafine grained materials ${ }^{[7]}$. The current ARB technology was mainly used in steel and aluminum alloy ${ }^{[8-10]}$, but it is relatively rare in electrical contact materials. In the present paper, the microstructure of $\mathrm{AgSnO}_{2}$ composites by ARB was studied and the density, hardness and electrical conductivity were tested.

\section{Experiment}

The silver powder with $45 \mu \mathrm{m}$ particle size and purity $>$ $99.95 \%$ and other reactants were used as starting materials

Received date: April 25, 2016

Foundation item: National Natural Science Foundation of China (51361016); Science Foundation of Key Laboratory of Rare-Precious and Nonferrous Metal Advanced Materials of Ministry of Education (ZDS2010014B); Analysis and Testing Foundation of Kunming University of Science and Technology (20140184, 20140301)

Corresponding author: Zhou Xiaolong, Ph. D., Professor, College of Materials and Engineering, Kunming University of Science and Technology, Kunming 650093, P. R. China, E-mail: kmzxlong@163.com 
to fabricate $\mathrm{AgSnO}_{2}$ composites by a reaction synthesis method. The content of $\mathrm{SnO}_{2}$ was $10 \mathrm{wt} \%$ in $\mathrm{AgSnO}_{2}$ composites. The raw powder was mixed in planetary ball mill, and the mixed raw powder was pressed as a cylindrical body at $310 \mathrm{MPa}$. Then the cylindrical body was sintered in a vacuum sintering furnace at $800 \mathrm{~K}$ for $2 \mathrm{~h}$. To increase the density of $\mathrm{AgSnO}_{2}$ composites, re-sintering and re-pressing were adopted. $\mathrm{AgSnO}_{2}$ sample of $\Phi 2.0 \mathrm{~mm} \times 209.5 \mathrm{~mm}$ was obtained by extrusion at different temperatures.

ARB process of primary $\mathrm{AgSnO}_{2}$ sample involved three main aspects. Firstly, 50\% reduction per pass was obtained by hot rolling with a rate of $1200 \mathrm{~mm} / \mathrm{min}$. Before the next step, the annealing treatment at $573 \mathrm{~K}$ was needed in order to avoid the influence of residual stress. Secondly, the sample after rolling was cut and stacked to be the initial thickness, which was treated as the raw sample for next step. Thirdly, ARB process was repeated 4 times at $973 \mathrm{~K}$. Before ARB process, the sample was preheated at $973 \mathrm{~K}$ for 5 min after annealing treatment at $573 \mathrm{~K}$.

The hardness of the samples was measured by Vivtorinox hardness tester ${ }^{[11]}$. The average value of sample density was calculated using size and quality of each sample, which were measured 5 times for ensuring the repeatability. The resistance of the $\mathrm{AgSnO}_{2}$ sample was measured using digital DC resistance tester (measuring accuracy: 0.02\%) at room temperature. Microstructure of $\mathrm{AgSnO}_{2}$ sample was observed using an optical microscope. X-ray diffraction (XRD) was used to analyze the phase composition of the sample.

\section{Results and Discussion}

\subsection{Phase analysis}

The X-ray diffraction results for $\mathrm{AgSnO}_{2}$ composites before ARB process is shown in Fig.1. From Fig.1, it is clear to see that the $\mathrm{AgSnO}_{2}$ composites can be fabricated by the reaction synthesis method and the phase composition are silver and tin oxide.

\subsection{Microstructure}

The microstructure of samples after different ARB processes is shown in Fig.2. From Fig.2, the $\mathrm{SnO}_{2}$ particles in $\mathrm{AgSnO}_{2}$ composites present an agglomeration state (A region in Fig.2a), but then they show a dispersed state with the increasing of roll pass (Fig.2b). Finally $\mathrm{SnO}_{2}$ particles exhibit an agglomeration state again (B region in Fig.2d).

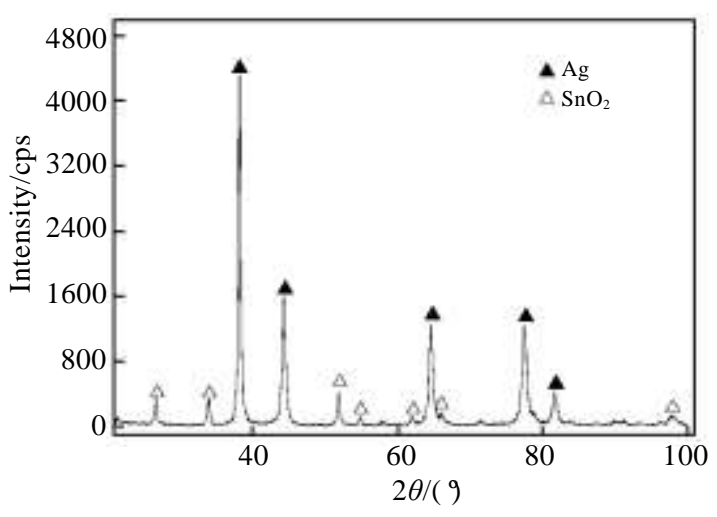

Fig.1 XRD pattern of the sample before ARB process

From Fig.2a to Fig.2b, the agglomerate $\mathrm{SnO}_{2}$ particles change into dispersed state through first pass ARB, namely $\mathrm{SnO}_{2}$ particles are evenly distributed in the silver matrix. The reason is that initial agglomerate $\mathrm{SnO}_{2}$ particles in the sample are probably dispersed by strongly stress of ARB process.

With the increasing of roll pass, the agglomerate $\mathrm{SnO}_{2}$ particles appear again (Fig.2d). This can be explained that the sample was cut and stacked after the first pass, which lead to overlap together of $\mathrm{SnO}_{2}$ particles in the next procedure.

\subsection{Property analyses}

\subsubsection{Density and hardness}

The density and hardness variation of samples after ARB process are shown in Fig.3. The density and hardness of $\mathrm{AgSnO}_{2}$ composites show an upward tendency with the increasing of rolling passes. The results can be summarized as follows:

On the one hand the frictional force is generated between the roller and the composites, which leads to the strong shear deformation in the $\mathrm{AgSnO}_{2}$ composites. The $\mathrm{SnO}_{2}$ particles are dispersed in $\mathrm{Ag}$ matrix with shear deformation. This causes the dislocation stacking near $\mathrm{SnO}_{2}$ particles and strengthens dispersion $^{[12]}$.

On the other hand the surface of the $\mathrm{AgSnO}_{2}$ composites is brought into the internal structure during the ARB process, which leads to plenty of compound interface in the $\mathrm{AgSnO}_{2}$ composites. Some impurities in roller surface are also brought
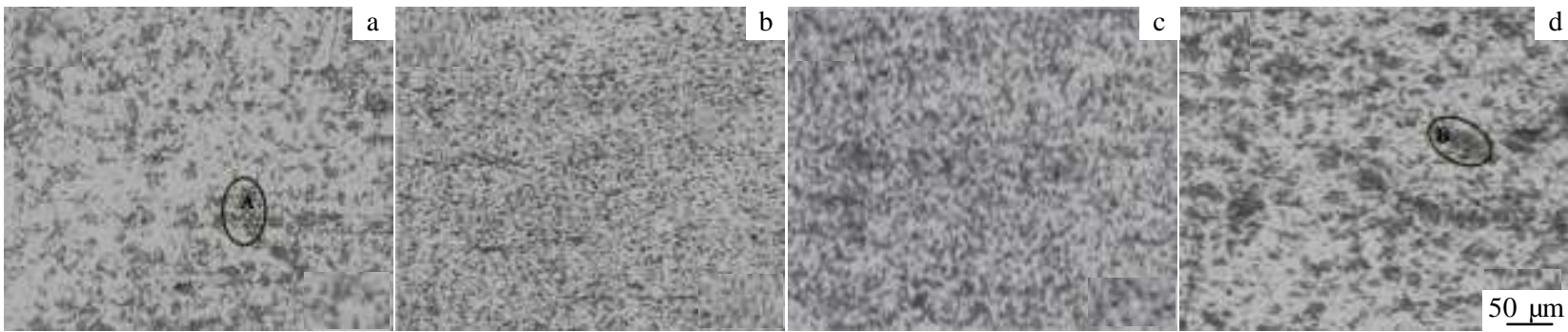

Fig.2 Microstructures of $\mathrm{AgSnO}_{2}$ during $\mathrm{ARB}$ at $973 \mathrm{~K}$ : (a) primary sample, (b) 1-pass, (c) 2-pass, and (d) 4-pass 


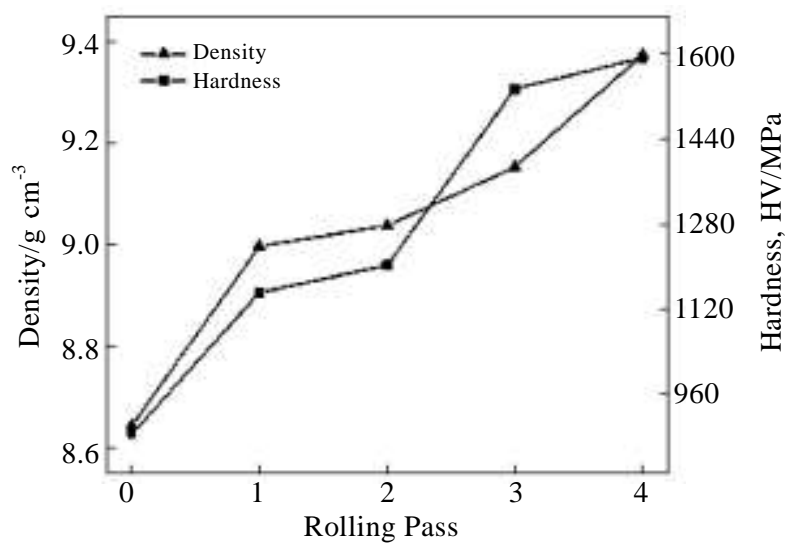

Fig.3 Relationship between density, hardness of $\mathrm{AgSnO}_{2}$ composites and rolling passes

into the inner of $\mathrm{AgSnO}_{2}$ composites under the rolling force. So the hardness of the samples increases gradually under the influence of the composite interface and impurities.

Hardness and density of the $\mathrm{AgSnO}_{2}$ sample are also affected by elimination of the pore structure, vacancies and other defects in the ARB process. Therein, the pores are one of the main defects in $\mathrm{AgSnO}_{2}$ composites by reaction synthesis. The disappearance of pores greatly improves the density and hardness of $\mathrm{AgSnO}_{2}$ composites in a certain extent due to the ARB process.

In addition, research shows that the changes of hardness is related to grain refinement as well as the changes of grain boundaries ${ }^{[13,14]}$. In $\mathrm{AgSnO}_{2}$ composites, the fine dislocation cell structure in the Ag matrix organization may be produced at the early pass of ARB process, which leads to dislocation pile at the next ARB process. With the increasing of strain, fine dislocation cells may be developed into ultrafine subgrains due to dislocation pile in $\mathrm{Ag}$ matrix. This will refine grains of Ag matrix, which produces fine grain strengthening and affects the hardness of $\mathrm{AgSnO}_{2}$ composites.

From Fig.3, the hardness (HV) of $\mathrm{AgSnO}_{2}$ composites changes from 884.364 MPa to $1150.992 \mathrm{MPa}$ with variation rate of $30.1 \%$ after the first rolling pass. But from the third to the fourth pass, the hardness changes from 1534.796 MPa to 1592.758 MPa with variation rate of only 3. 89\%. It seems that the ARB process does not definitely increase the hardness of $\mathrm{AgSnO}_{2}$ composites. It is attributed to the common role of elimination of the pore structure or vacancies and significant grain refinement at the first rolling pass. There is no elimination of the pore structure or vacancies at the third to the fourth pass due to density increase after the second rolling pass.

\subsubsection{Resistivity}

Rolling pass effect on resistivity of $\mathrm{AgSnO}_{2}$ composites is shown in Fig.4. The resistivity of the $\mathrm{AgSnO}_{2}$ composites increases after an initial decrease during the ARB process.

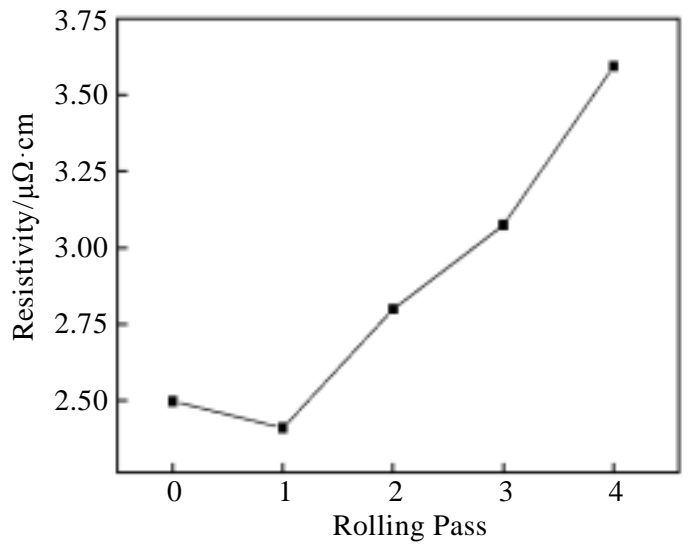

Fig.4 Relationship between resistivity of $\mathrm{AgSnO}_{2}$ composites and rolling passes

The resistivity of sample declines from $2.498 \mu \Omega \cdot \mathrm{cm}$ to $2.411 \mu \Omega \cdot \mathrm{cm}$ after the first pass. This is attributed to a high density, microstructure homogenization, and few structure defects of $\mathrm{AgSnO}_{2}$ composites through $\mathrm{ARB}$. Then the resistivity of $\mathrm{AgSnO}_{2}$ composites increases, which results from the residual stress and $\mathrm{SnO}_{2}$ particles agglomeration again (Fig.2).

The rolling process can produce strong strain and poor wettability between the $\mathrm{Ag}$ and $\mathrm{SnO}_{2}$. It is inevitable that $\mathrm{SnO}_{2}$ particles are enriched in the $\mathrm{AgSnO}_{2}$ samples during rolling process. This leads to the stress concentration in partial area of the $\mathrm{AgSnO}_{2}$ composites. Quinn et $\mathrm{al}^{[15]}$ suggested that the resistance of the metal originates from ion scattering of conduction electrons. Stress concentration causes the interface distortion of $\mathrm{AgSnO}_{2}$ composites, which leads to electronic strong scattering and finally increases the resistivity of $\mathrm{AgSnO}_{2}$ samples.

In the metal matrix composites, electronic transmission can be reduced because of the interface scattering. This scattering process has become the main factor affecting the resistivity of composites. For $\mathrm{AgSnO}_{2}$ composites, $\mathrm{SnO}_{2}$ particles are gradually dispersed during ARB process (Fig.2), which leads to plenty of interface increase between $\mathrm{SnO}_{2}$ and the $\mathrm{Ag}$ matrix, and then increases the resistivity of $\mathrm{AgSnO}_{2}$ composites.

In addition, the distribution of $\mathrm{SnO}_{2}$ particles may impact the resistivity of $\mathrm{AgSnO}_{2}$ composites. Before ARB process, $\mathrm{SnO}_{2}$ particles are distributed in the silver matrix with three-dimensional network structure. However, due to stack, it shows a kind of layered structure after ARB process.

\section{Conclusions}

1) $\mathrm{AgSnO}_{2}$ composites with a homogeneous structure are obtained by ARB. During the ARB process, the $\mathrm{AgSnO}_{2}$ composites are rolled with a 50\% reduction ratio per pass at $973 \mathrm{~K}$. Then, the rolled sheet is cut and stacked to the initial thickness, and the stacked piece is rolled again. But after 
4-passes rolling, $\mathrm{SnO}_{2}$ particles agglomerate again in the structure of $\mathrm{AgSnO}_{2}$ composites.

2) During $\mathrm{ARB}$ at the constant rolling temperature, the hardness and density of $\mathrm{AgSnO}_{2}$ sample increase with the increasing of rolling pass. This is attributed to the elimination of the pore structure, vacancies and other defects, as well as dispersion strengthening and fine grain strengthening.

3) The resistivity change is dominated by the contribution of $\mathrm{SnO}_{2}$ particles in the $\mathrm{AgSnO}_{2}$ composites and interface scattering.

\section{References}

1 Slade P G. Electrical Contacts: Principles and Applications[M]. Florida: Crc Press Taylor \& Francis Group, 2013: 233

2 Rong Mingzhe. Theory of Electrical Contact[M]. Beijing: China Machine Press, 2004: 125 (in Chinese)

3 Hasegawa M. The 27th International Conference on Electrical Contacts[C]. Dresden: VDE VERLAG, 2014: 1

4 Zhang Kunhua, Guan Weiming, Sun Jialin et al. Rare Metal Materials and Engineering [J], 2005, 34(6): 924 (in Chinese)

5 Wang Haitao, Wang Huihui. The 26th International Conference on Electrical Contacts[C]. Beijing: Institution of
Engineering and Technology, 2012: 406

6 Wang Song, Chen Youtai, Yang Youcai et al. Precious Metals[J], 2013, 34(S1): 102 (in Chinese)

7 Min G, Lee J M, Kang S B et al. Materials Letters[J], 2006, 60(27): 3255

8 Wu K, Chang H, Maawad E et al. Materials Science and Engineering $A[\mathrm{~J}], 2010,527(13): 3073$

9 Zhan Meiyan, Li Chunming, Zhang Weiwen et al. Journal of Materials Engineering[J], 2012, 40(1): 18 (in Chinese)

10 Xu Rongchang, Tang Di, Ren Xueping et al. Journal of University of Science and Technology Beijing [J], 2007, 29(3): 310 (in Chinese)

11 Sun Shicheng, Sun Guixun, Jiang Zhonghao et al. Chinese Physics B[J], 2014, 23(2): 379 (in Chinese)

12 Xu Canhui, Yi Danqing, Cao Shiyi et al. The Chinese Journal of Nonferrous Metals[J], 2011, 21(9): 2091 (in Chinese)

13 Park K T, Kwon H J, Kim W J et al. Materials Science and Engineering $A[\mathrm{~J}], 2001,316(1-2): 145$

14 Song Hongwu, Chen Yan, Cheng Ming et al. Materials Review[J], 2011, 25(19): 7 (in Chinese)

15 Quinn J J, Yi K S. Free Electron Theory of Metals[M]. Berlin: Springer Berlin Heidelberg, 2009: 79

\title{
累积叠轧工艺对 $\mathrm{AgSnO}_{2}$ 复合材料组织与性能的影响
}

\author{
周晓龙 ${ }^{1,2}$, 陶麒鹦 ${ }^{1}$, 周允红 ${ }^{1}$
}

(1. 昆明理工大学 材料科学与工程学院, 云南 昆明 650093)

(2. 昆明理工大学 稀贵及有色金属先进材料教育部重点实验室 云南省新材料制备与加工重点实验室，云南 昆明 650093)

摘 要: 以反应合成所制备的 $\mathrm{AgSnO}_{2}$ 复合材料为研究对象, 采用XRD、光学显微镜与物理、力学性能测试分析手段, 分析了反应合成 $\mathrm{AgSnO}_{2}$ 复合材料的物相, 温度为 $973 \mathrm{~K}$ 条件下 $\mathrm{AgSnO}_{2}$ 复合材料经过4道次累积叠轧后的显微组织及密度、硬度、电阻率等性能。结果表 明: 累积叠轧工艺对反应合成 $\mathrm{AgSnO}_{2}$ 复合材料显微组织与物理性能有显著影响; 累积叠轧道次影响着增强相 $\mathrm{SnO}_{2}$ 在银基体中的分布状 态, 叠轧不仅能够促使 $\mathrm{SnO}_{2}$ 在银基体中弥散化分布, 也会由于叠层导致 $\mathrm{SnO}_{2}$ 的二次团聚; 其密度、硬度均随着累积叠轧次数增多而升 高, 电阻率在第1次叠轧时有所降低, 随后随着累积叠次数增多而升高。

关键词: 反应合成法; $\mathrm{AgSnO}_{2}$ 复合材料; 累积叠车

作者简介: 周晓龙, 男, 1969 年生, 博士, 教授, 昆明理工大学材料科学与工程学院, 云南 昆明 650093, E-mail: kmzxlong@163.com 